\title{
UAV FLIGHT CONTROL BASED ON ARDUINO BOARD IMPLEMENTATIONS
}

\author{
Michail Papoutsidakis \\ Dept. of Industrial Design and \\ Production Engineering, \\ University of West Attica \\ Athens, Greece
}

\author{
Avraam Chatzopoulos \\ Dept. of Industrial Design and \\ Production Engineering, \\ University of West Attica \\ Athens, Greece
}

\author{
Dimitrios Piromalis \\ Dept. of Industrial Design and \\ Production Engineering, \\ University of West Attica \\ Athens, Greece
}

\begin{abstract}
The paper presents the analysis of the operation and implementation of a flying autonomous robotic vehicle or unmanned aerial vehicle. The purpose in its final form is to allow the vehicle to take off, swing holding steady its position, move in the space in case it approaches a moving object and finally to land smoothly. Commands will be taken entirely from a computing platform with a built-in microcontroller that will communicate directly with the vehicle's sensors and will be responsible for controlling them.
\end{abstract}

\section{Keywords - Watermarking, Haar Wavelet, DWT, PSNR}

\section{INTRODUCTION}

The subject that will concern us and analyze in this project concerns Unmanned Flying Vehicles or, as has been the case in recent years, drones. In particular, we will show how we can properly build and program such a vehicle, as well as what we should take into consideration in order to our construction has the ability of flotation. Both the proper programming and the criteria by which the correct sensors are selected will be analyzed.

The idea of drones began several years ago and specifically back in 1971 from the scientist of nuclear physics John Stuart

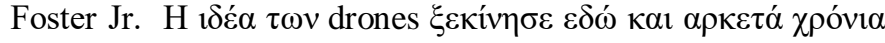

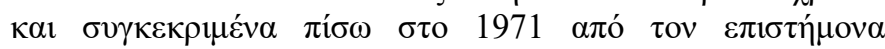

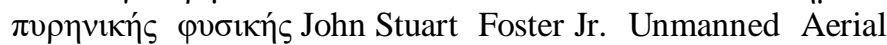
Vehicle means any type of flying vehicle that does not have a pilot on its spindle, but operates either autonomously or by means of a remote control. The term unmanned flying vehicle only describes the aircraft without a pilot. The term Unmanned Flying System (UAS) includes all devices, personnel and procedures used to ensure that the unmanned aircraft is considered as a complete system. Also, the term RPAS was established in accordance with the applicable law due to the rapid increase in the use of unmanned vehicles in recent years and the need for at least one operator to supervise the flight of such vehicles. There is a wide variety of them and they are divided into two categories, military and political. They are also distinguished in small airplanes or helicopters with one or more propellers and controlled by a microcontroller, whether autonomous or remote controlled. The reasons why an approach such as this one is interesting, apart from the effort to build and operate an autonomous Drone, is quite a number of areas, since there is a wide variety of applications. For example, the use of unmanned flying robotic vehicles in the field of medicine, research applications for the mapping of inaccessible areas and their use by security forces is of great interest.

It is worth noting that our goal, with the completion of the project, is the supposed unmanned flying vehicle to carry a microprocessor and appropriate sensors through which checks will be made. Specifically, it is given the opportunity to enter into operation by a suitable audio signal, rising from the ground to the corresponding distance which is set, it remains stable in this position considering it as resting state and to move to another spot if it realizes that something is moving towards it. Finally, with the same audible signal will be turned off after first checking for a possible obstacle when landing.

\section{THE DRONES TODAY}

\section{A. Use of Drones}

Today, Unmanned Flying Vehicles or drones have many and various applications at a global level. The cases that apply to the use of a drone are both for simple freight transport and for dealing with natural disasters such as an earthquake, fires, floods, tsunamis and similar emergencies. It could be used as courier service that cannot be blocked due to congestion, making it easier and quicker to supply essential necessities. It is also effective in times of war or crisis due to the lack of water, food and even medical supplies such as human organ transport for transplants and fast-track medical examinations in inaccessible areas. 


\section{International Journal of Engineering Applied Sciences and Technology, 2019 \\ Vol. 4, Issue 5, ISSN No. 2455-2143, Pages 438-443 \\ Published Online September 2019 in IJEAST (http://www.ijeast.com)}

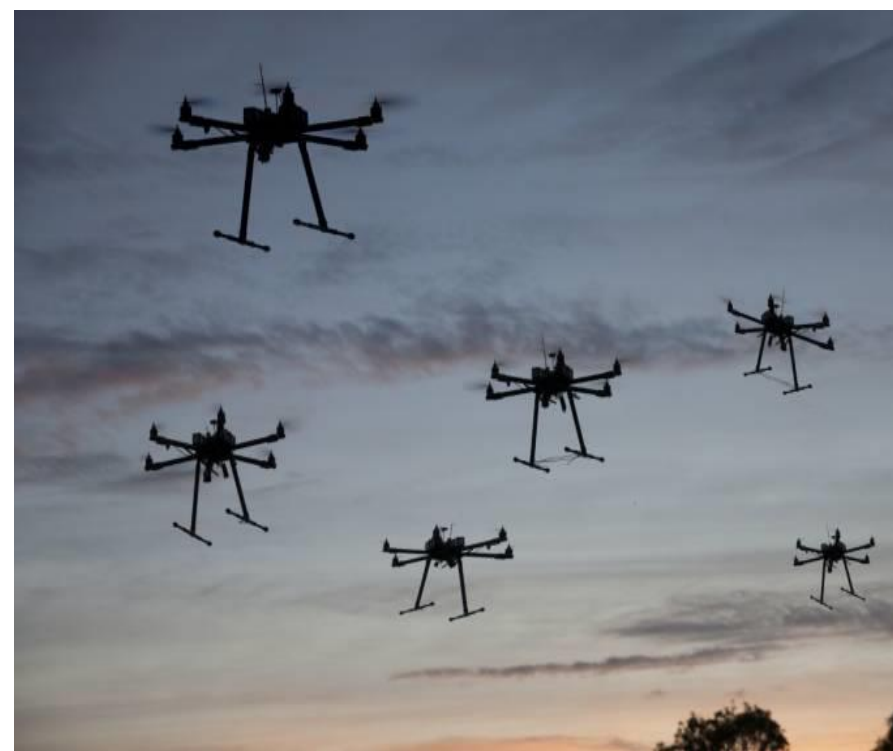

Even in wars, they are being used by intelligence agencies in many countries for espionage or bombing. Depending on the requirements of their mission, drones can be equipped with different kinds of specialized and non-compatible sensors and sensing devices. For example, optical and infrared cameras, thermal and acoustic sensors, microphones, infrared and ultrasonic sensors, Wifi and GPS. This makes them safe, reliable, and more autonomous on flights with better adaptability. It is possible through the controls to immediately deal with any errors, to anticipate their movements in order to avoid obstacles and turbulence, and finally to create flight maps that define the route and the purpose of their flight based on some filters (information collected by algorithms through sensors).

\section{B. Possible Problems - Risks}

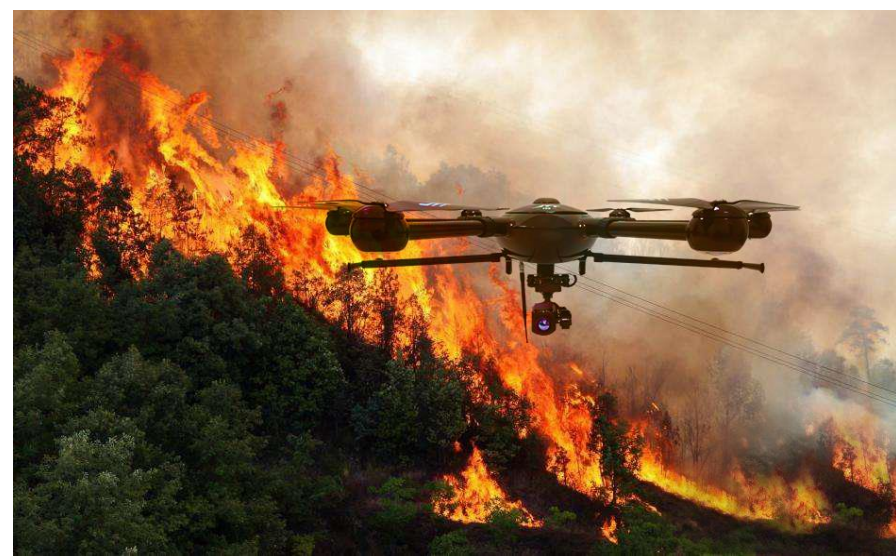

Despite the advantages of using drones, there is still a negative side, problems and dangers in their use. There may be simple problems, such as some technical damage, that unmanned aircraft due to the absence of an operator cannot be corrected in a timely and effective manner. There have been incidents due to the lack of appropriate sensors, where drones have entered the airspace of state or international airports, creating traffic problems. But there are even more serious problems, such as the use of military drones, where a mistaken execution of a target can bring destruction of buildings and even human losses. Even more dangerous is the interest shown by terrorist organizations in the use of drones, due to their evolving capabilities, such as massive attacks and attacking targets that are distant from the ground. In particular, the drones have a large range, precision and small size that helps in the secret of the attack. Based on all the above and in conjunction with the legal gap that still exists, the use of drones is uncontrollable.

\section{MODULE 2}

\section{A. Mechanical Parts of which Consist of Construction}

As the title of the thesis shows, the robot that was made was meant to be a flyer, so it is also referred to as a flying autonomous robotic vehicle. Therefore, from the initial designs that were made, the size and weight of the construction was limited for obvious reasons, some of them being the possibility of swing, the autonomy and the cost of construction. It could therefore consist of an improvised wooden structure or a plastic structure or something made by a kind of alloy, some metal, copper, or aluminum. However, problems arose in the center of gravity, the stability of the construction of its individual parts through the joints, its total weight, but also the cost.

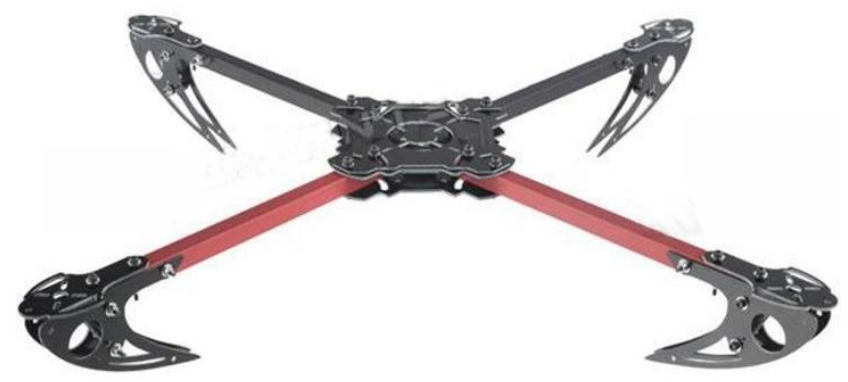

In order to avoid all the above problems, the construction was purchased ready-made on request and consists of pieces with absolute symmetry between each other in order to achieve the best results. Thus, the structure consists of four square aluminum tubes used as arms, motor mounts at their ends where at the bottom they fit pieces used as "legs" and carry plates to cushion the crash during landing and finally the base of the Arduino board, the central unit of the quadcopter consisting of two parts. In addition to the arms, the remaining 


\section{International Journal of Engineering Applied Sciences and Technology, 2019 \\ Vol. 4, Issue 5, ISSN No. 2455-2143, Pages 438-443 \\ Published Online September 2019 in IJEAST (http://www.ijeast.com)}

individual parts are made of carbon fiber for high strength, breaking strength and particularly light weight.

\section{B. Electronic Parts}

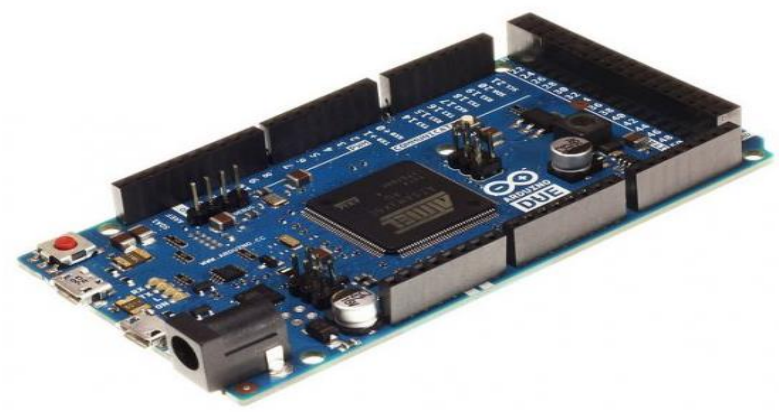

The electronic parts that were necessary for the completion, the control and the correct function of the drone, are as follows :

- A programmable board that is the drone's control unit. As a control center of the entire construction we selected an Arduino board, which can receive data from input units, process them and send them with appropriate commands to its output units.

- Electric motors with sufficient power for the requirements of the drone. Thus, DC motors with a power of $980 \mathrm{KV}$ per motor were selected, with their speed in mind and the total weight of the structure to be checked, in combination with their power consumption requirements.

- A controller that regulates the motor's speed, direction and braking. The ESC is an engine control board that has a power input and a three-phase output for each engine. Each ESC is independently controlled by a PPM similar to PWM. Signal frequencies vary greatly, but for a Quadcopter it is recommended that the controller should support a sufficiently high signal frequency so that engine speeds are adjusted faster for optimal stability (ie at least 200 to $300 \mathrm{~Hz}$ PPM signal).

- Ultrasound sensors which control distances and possible obstacles. In order to identify objects in the room, avoid them and measure the distance from the ground, sensors, accurate to their measurements, such as the ultrasonic sensor HC-SR04, should be selected.

- Sensor for controlling the balance and stability of the drone. Another sensor needed to control the balance, a 2-axis gyro sensor was used for this purpose. The gyroscope is called LPY503AL and what it does is measure the angular velocity of the axes.

- Audio detection to start up and shut down drone operation. The following sensor is an audio detection sensor, which is designed to generate an output signal when the receiver detects an audio signal.

- A battery for powering the control unit, which is necessary to put all the above into operation. For the power supply that makes it both the microcontroller and the individual sensors as well as the motors it carries, a battery with a capacity of $4200 \mathrm{mAh}$ with an output voltage of 11.1 Volt was selected.

- Programming environment and the software to fully control the drone.

Arduino's integrated development environment (IDE) is written in Java and can run on multiple platforms. It includes a code editor (a word processor with various handy tools) and a compiler, it also has the ability to easily load the program via a USB port or a serial port from the PC to the PCB.

The development environment is Processing-based, a development environment designed to introduce new users who are not familiar with software development. This programming language comes from Wiring, a C-like language, however, has some modifications, as mentioned above, which provides similar functionality for a more limited design board, whose development environment is also based on Processing.

Below, we analyze a part of the program that is responsible for the drone's main operation. This part is responsible for the input and output signals of all the sensors and the calibration of the motors with their controller.

void setup ()

$\{\{$

Serial.begin (9600);

With the pinMode command, we define the pin that we use to act as INPUT or OUTPUT.

pinMode (echo_front_Pin, INPUT); // With this command, we define the echo_front_Pin to act as an input to the microcontroller.

pinMode (trig_front_Pin, OUTPUT); // And trig_front_Pin is set to act as the output of the microcontroller. 


\section{International Journal of Engineering Applied Sciences and Technology, 2019 \\ Vol. 4, Issue 5, ISSN No. 2455-2143, Pages 438-443 \\ Published Online September 2019 in IJEAST (http://www.ijeast.com)}

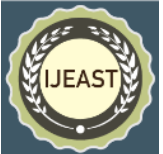

pinMode (echo_back_Pin, INPUT); // With this command, we set the echo_back_Pin to act as an input to the microcontroller.

pinMode (trig_back_Pin, OUTPUT); // And trig_back_Pin is set to act as the output of the microcontroller.

pinMode (echo_down_Pin, INPUT); // With this command, we set the echo_down_Pin to act as input to the microcontroller.

pinMode (trig_down_Pin, OUTPUT); // And trig_down_Pin is set to act as the output of the microcontroller.

pinMode (sound_in, INPUT); // We define the signal from the sound sensor as input to the microcontroller.

pinMode (motor1Pin, OUTPUT); // With this command, we define the output of the motor1Pin that connects to the PWM 2 port.

pinMode (motor2Pin, OUTPUT); // With this command we define the motor2Pin that connects to the PWM port 3 as the output.

pinMode (motor3Pin, OUTPUT); // With this command we define the output of the motor3Pin that is connected to the PWM 4 port.

pinMode (motor4Pin, OUTPUT); // This command defines the output of the motor4Pin that connects to the PWM port 5.

initialize_escape (); // At this point we call the initialize_escape () function with which we create an image of the state of our motors.

apostash_front $=$ sonar (trig_front_Pin, echo_front_Pin);// The call to the sonar function (), executed below, returns the distance value from the sensor to the probable obstacle and is assigned to the apostash_front variable.

apostash_back = sonar (trig_back_Pin, echo_back_Pin); // The function called sonar (), executed below, returns the distance value from the sensor to the probable obstacle and is assigned to the apostash_back variable.

apostash_down = sonar (trig_down_Pin, echo_down_Pin); // The call to the sonar function (), executed below, returns the distance value from the sensor to the probable obstacle and is assigned to the apostash_down variable.

$$
\text { \} }
$$

\section{MODULE 3}

\section{A. Future Use of Drones}

The drones have come to stay and now we are going through an era full of surprises and innovations. Drones, or unmanned aerial vehicles, are entering rapidly into our lives. Like any new technology, drones "promise" to change our future, and they are already fast moving to there. The global market in
2016 was estimated at just over 2 billion euros and is expected to exceed 110 billion by 2020 .

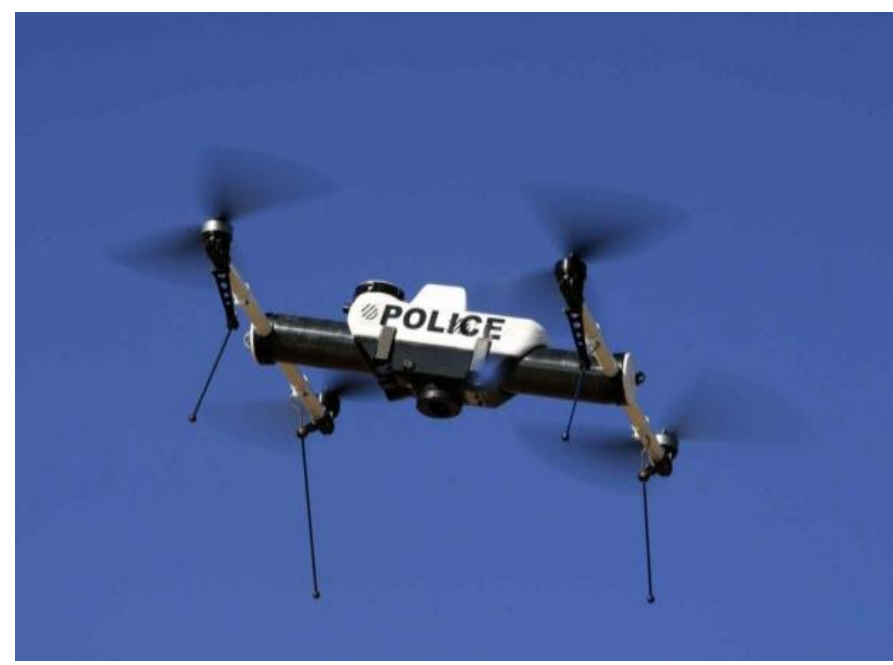

As mentioned and explained in the previous chapters, drones technologies cover a wide range of applications such as: Security, Surveillance, Defense, Rescue , Construction, Agriculture, Energy, Environment, Topography, Aerial Photography, Television, Cinema. The development of Drones technology in the coming years will be rapid, resulting in an increased range of applications. Presentations that have been made occasionally by specialists in the field have become interesting applications for the future. For example, some of these are their use for border surveillance, inaccessible and non-mapping, various environmental studies, applications in agriculture and applications for national or international freight transport.

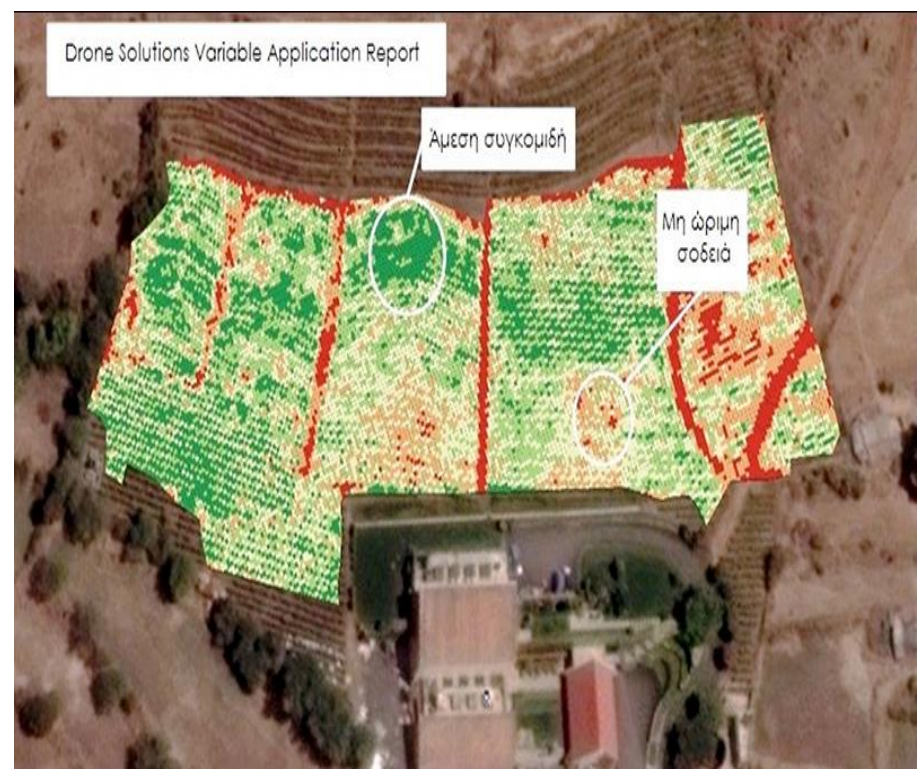




\section{International Journal of Engineering Applied Sciences and Technology, 2019 \\ Vol. 4, Issue 5, ISSN No. 2455-2143, Pages 438-443 \\ Published Online September 2019 in IJEAST (http://www.ijeast.com)}

\section{CONCLUSIONS}

Summarizing, everyone's point of view may differ on how technology can be used and significantly affect our lives. So, Non-Manned Flying Vehicles, as analyzed above, do not only positively affect our lives, but in many cases also negatively.

It is clear that they were invented to help our lives in many areas. In fact, in some of these, the results are much better than initial expectations. For example, in security, surveillance, rescue even in army operations and espionage. These results are possible because of low cost of construction and operation, low weight, size variation according each time application and their characteristic not to endanger the operator's physical integrity. Also, a great advantage is that their manufacturing capability cannot be detected by tracking systems. In addition, another reason contributing to these results is the fact that in certain cases with a small size of drone construction, it is possible to be placed many sensors, which enable them to carry out many specialized applications.

However, it is equally important to take into account the negative consequences because they affect our lives. Although there is relative legislation on Non-Manned Flying Vehicles in most countries, there is a very large gap in our country in terms of proper use and possession, as well as their legislative and insurance coverage. In particular, there is insufficient state control as well as appropriate information from the responsible bodies, which is why it is often dangerous to use drones in our country for both people and air traffic. There is no control on the market of a drone, for example there is no single serial number for each Unmanned Aerial Vehicle, so that the owner can easily be identified. Based on this, the potential holders of a drone may be from underage children to terrorist organizations. With the uncontrolled use of drone, anyone can fly a drone without a pilot's license or even a flight permit, making photo and video downloads by violating copyrights.

\section{ACKNOWLEDGMENTS}

All authors would like to thank the University of West Attica for the financial support provided to them for this research project.

\section{REFERENCE}

[1] Amanatidis, Ch., (2018), Real Estate and Environment reading: Unmanned aircraft (drones), https://www.taxydromos.gr/Perivallon/295584-akinhtwnkai-periballontos-to-anagnwsma-mh-epandrwmenaaeroskafh-drones.html

[2] These are the flight rules of the drones, (2016), http://www.ant1news.gr/news/Society/article/454771/ayto i-einai-oi-kanones-ptisis-ton-drones
[3] Vetos, B., (2017), Drones: How to fly TODAY in Greece without being illegal, https://www.pttl.gr/how-to-fly-adrone-in-greece-at-the-moment-03551/

[4] Wikipedia, (2018), Unmanned Aerial Vehicle, https://el.wikipedia.org/wiki/\%CE\%9C\%CE\%B7_\%CE\% B5\%CF\%80\%CE\%B1\%CE\%BD\%CE\%B4\%CF\%81\%C F\% 89\% В1\%СЕ\%В5\%СF\%81\%СЕ\%ВF\%СF\%83\%СЕ\%ВA\%С $\mathrm{E} \% \mathrm{AC} \% \mathrm{CF} \% 86 \% \mathrm{CE} \% \mathrm{BF} \% \mathrm{CF} \% 82$

[5] Wikipedia, (2018), Agricultural drone, https://en.wikipedia.org/wiki/Agricultural_drone

[6] Are the drones the future of war operations? Will the troops trust them? (photo, video), (2018), https://www.pronews.gr/amynaasfaleia/aeroporia/669462_giati-ta-drones-einai-mellonton-polemikon-epiheiriseon-tha-ta

[7] ELEFTHERIA online, (2018), The present and the future of drones, https://www.eleftheriaonline.gr/elladakosmos/tech/item/168280-to-paron-kai-to-mellon-tondrones

[8] Karagiannopoulos, B., (2016), The drones are the future, https://www.insider.gr/apopseis/vlogs/12808/ta-droneseinai-mellon

[9] Katsoudas, A., (2018), Drones: Attack on our private life or a useful tool ?, https://www.lifo.gr/articles/technology_articles/208316/dr ones-epithesi-stin-idiotiki-mas-zoi-i-xrisimo-ergaleio

[10] Red, S., \& Long, B., (2018), The use of drones in modern agriculture, http://agrotes.eu/i-chrisi-ton-drones-stisygchroni-georgia/

[11] Xanthakis, B., (2016), Drones for Surveillance and Safety, https://www.securitymanager.gr/drones-giaepitirisi-ke-asfalia/

[12] Xouris, X, (2018), Transforming modern agriculture, https://www.gaiarobotics.gr/\%CE\%BC\%CE\%B5\%CF\%8

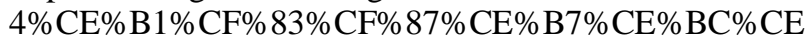
$\% \mathrm{~B} 1 \% \mathrm{CF} \% 84 \% \mathrm{CE} \% \mathrm{AF} \% \mathrm{CE} \% \mathrm{~B} 6 \% \mathrm{CE} \% \mathrm{BF} \% \mathrm{CE} \% \mathrm{BD}$ $\% \mathrm{CF} \% 84 \% \mathrm{CE} \% \mathrm{~B} 1 \% \mathrm{CF} \% 82-$

$\% \mathrm{CF} \% 84 \% \mathrm{CE} \% \mathrm{~B} 7 \% \mathrm{CE} \% \mathrm{BD}-$

$\% \mathrm{CF} \% 83 \% \mathrm{CF} \% 8 \mathrm{D} \% \mathrm{CE} \% \mathrm{~B} 3 \% \mathrm{CF} \% 87 \% \mathrm{CF} \% 81 \% \mathrm{CE} \%$ $\mathrm{BF} \% \mathrm{CE} \% \mathrm{BD} \% \mathrm{CE} \% \mathrm{~B} 7-$ $\%$ СE\%B3\%CE\%B5\%CF\%89\%CF\%81/

[13] Papacharalambous, TH, (2017), Drones and Environmental Protection, https://powerpolitics.eu/drones-

$\% \mathrm{CE} \% \mathrm{BA} \% \mathrm{CE} \% \mathrm{~B} 1 \% \mathrm{CE} \% \mathrm{~B} 9$

$\% \mathrm{CF} \% 80 \% \mathrm{CF} \% 81 \% \mathrm{CE} \% \mathrm{BF} \% \mathrm{CF} \% 83 \% \mathrm{CF} \% 84 \% \mathrm{CE} \% \mathrm{~B}$

$1 \% \mathrm{CF} \% 83 \% \mathrm{CE} \% \mathrm{AF} \% \mathrm{CE} \% \mathrm{~B} 1-$

$\% \mathrm{CF} \% 84 \% \mathrm{CE} \% \mathrm{BF} \% \mathrm{CF} \% 85$

\%СF\% $80 \%$ СЕ\%В5\%СF\%81\%СЕ\%В9\%СЕ\%В2\%СЕ\% $\mathrm{AC} \% \mathrm{CE} \% \mathrm{BB} \% \mathrm{CE} \% \mathrm{BB} \% \mathrm{CE} \% \mathrm{BF} \% \mathrm{CE} \% \mathrm{BD} \% \mathrm{CF} \% 84 \%$ $\mathrm{CE} \% \mathrm{BF} \% \mathrm{CF} \% 82 /$ 
International Journal of Engineering Applied Sciences and Technology, 2019

Vol. 4, Issue 5, ISSN No. 2455-2143, Pages 438-443

Published Online September 2019 in IJEAST (http://www.ijeast.com)

[14] Pliakos, K., (2016), In the era of the drones, https://www.cnn.gr/focus/story/31040/stin-epoxi-tondrones

[15] Margaritoff, M., (2018), Drones in Agriculture: How UAVs Make Farming More Efficient, http://www.thedrive.com/tech/18456/drones-inagriculture-how-uavs-make-farming-more-efficient 